\title{
Inteligencia artificial y derecho. Problemas, desafíos y oportunidades*
}

\section{Artificial Intelligence and Law. Problems, Challenges and Opportunities}

\author{
Dario Parra Sepúlveda ${ }^{\text {a }}$ \\ Universidad Austral de Chile, Chile \\ dario.parra@uach.cl \\ ORCID: https://orcid.org/0000-0003-4024-570X \\ Ricardo Concha Machuca \\ Universidad de Concepción, Chile \\ ORCID: https://orcid.org/0000-0002-6431-2535
}

DOI: https://doi.org/10.11144/Javeriana.vj70.iadp

Recibido: 05 Septiembre 2020

Aceptado: 11 Marzo 2021

Publicado: 29 Octubre 2021

\section{Resumen:}

El desarrollo tecnológico está dando lugar a una profunda transformación de nuestra sociedad. Y una de las tecnologías más determinantes en la actualidad es la inteligencia artificial. El uso intensivo de esta tecnología, tanto en actividades complejas como en situaciones cotidianas, ha dado lugar a relaciones jurídicas no contempladas en nuestros marcos normativos. En este contexto, se estudian los principales problemas que plantea la inteligencia artificial a los sistemas jurídicos. La revisión se hace por medio de tres casos prácticos. Finalmente, se analizan los desafíos que se presentan al derecho, con la expansión de la inteligencia artificial.

Palabras clave: inteligencia artificial, cambio social, derecho, tecnología.

\begin{abstract}
:
Technological development is leading to a profound transformation of our society. And one of the most determining technologies today is artificial intelligence. The intensive use of this technology, both in complex activities and in everyday situations, has given rise to legal relationships not contemplated in our normative frameworks. In this context, the main problems posed by artificial intelligence to legal systems are studied. The review is done through three practical cases. Finally, the challenges presented to the Law are analyzed, with the expansion of artificial intelligence.
\end{abstract}

Keywords: artificial intelligence, social change, law, technology.

\section{Introducción}

Históricamente ha existido una compleja relación entre el derecho y el cambio social ${ }^{1}$. La adaptación de los ordenamientos jurídicos a la realidad social, intrínsecamente cambiante, es uno de los más importantes desafíos que han enfrentado desde siempre quienes crean, interpretan o aplican el derecho ${ }^{2}$.

Aunque en algunas ocasiones la norma ha forjado la transformación de la sociedad, como ocurre cuando la ley establece incentivos para lograr determinadas conductas de los ciudadanos, la regla general es que sea necesaria la adaptación del derecho, ante los desafíos que plantea la constante evolución de las sociedades humanas $^{3}$. De esta forma, es común caracterizar a la norma jurídica con una cierta rigidez e inmovilidad, y constatar que muchas veces esta se muestra "impotente para seguir de cerca la incesante evolución de las necesidades jurídicas" ${ }^{4}$.

Los avances de la ciencia y la tecnología han acelerado los procesos de transformación social, exigiendo al máximo la adaptabilidad de los sistemas normativos ${ }^{5}$. Somos una sociedad cada vez más dinámica, cambiante, que ha ido asumiendo nuevos riesgos e incorporando nuevos valores ${ }^{6}$. La globalización, el cambio climático, internet, las redes sociales, el uso cotidiano de la tecnología, entre otros fenómenos, han sido fuente de nuevas formas de relaciones jurídicas, que parecen superar las posibilidades del derecho.

Notas de autor

\footnotetext{
${ }^{a}$ Autor de correspondencia. Correo electrónico: dario.parra@uach.cl
} 
Así, por ejemplo, los tribunales de justicia han debido dotar de nuevos contenidos a los derechos a la honra, a la intimidad y a la propia imagen, frente al escrache que sufren las personas en las redes sociales, utilizado como mecanismo de autotuleta ${ }^{7}$. Los adelantos científicos y tecnológicos en medicina han dado lugar a nuevos paradigmas éticos y jurídicos en torno a la vida y la manipulación genética ${ }^{8}$. El uso generalizado de internet en el comercio ha obligado a regular la utilización de bases de datos con información relativa a la vida privada de las personas, adaptar las reglas tributarias, establecer nuevas modalidades de contratación o ampliar el catálogo de derechos del consumidor?.

La ascensión de una sociedad que comienza a relacionarse intensamente con la tecnología, ha dado lugar a problemas jurídicos complejos y globales, que parecen aumentar la brecha entre cambio social y derecho ${ }^{10}$. Bennet, haciendo un símil con la fábula de la liebre y la tortuga, señala que la norma se presenta como la eterna perdedora en la carrera sin fin contra la tecnología. Mientras esta da lugar a importantes transformaciones sociales, que involucran nuevas formas de conducta de las personas, el derecho continúa siendo dirigido a resolver viejos problemas, incapaz de mantenerse al día con el mundo moderno ${ }^{11}$.

En este marco de relaciones entre derecho y cambio social, nos centramos en el cambio tecnológico. Como advierte Bennet, se trata de un tipo de cambio social, referido a lo que la sociedad es técnicamente capaz de hacer en un momento concreto ${ }^{12}$. Por tanto, nos interesan las interacciones del derecho con las transformaciones de las estructuras sociales relacionadas con el desarrollo de la ciencia y la técnica.

Si bien es cierto, el ordenamiento jurídico ha intentado adaptarse al cambio tecnológico, como sucede con la legislación relativa a protección de datos o la contratación electrónica, es necesario llevar a cabo un proceso general de adaptación del derecho a la sociedad de hoy, tecnológica, digitalizada, virtual. El sistema normativo debe integrar los nuevos desafíos que nos proponen la ciencia y la técnica, acomodándose a sus contenidos y a sus tiempos. Entender las nuevas relaciones sociales, ajustarse a ellas y proponer soluciones innovadoras y creativas, dando lugar a sistemas jurídicos flexibles y dinámicos. En definitiva, repensar el derecho, desde una perspectiva sustancial y formal, para dar respuestas coherentes a los requerimientos de la vida actual y proyectar las transformaciones futuras.

En este contexto, el objeto del presente trabajo es revisar algunos de los principales retos que enfrenta el derecho, como ciencia, ante el progreso científico y tecnológico. En concreto, se abordan las dificultades y los desafíos que se presentan a los sistemas jurídicos, con el uso de la inteligencia artificial (IA), que se ha expandido a casi todos los aspectos de nuestra vida.

El estudio se inicia con una aproximación al concepto de inteligencia artificial (IA), desde una perspectiva jurídica. A continuación, se revisan algunos de los principales problemas que se han presentado con el uso de este tipo de inteligencia, mediante la revisión de tres casos concretos. Finalmente, se identifican los principales desafíos normativos que los sistemas de inteligencia artificial plantean y las diversas iniciativas que promueven el diseño de una normativa base que oriente la regulación relativa a la IA.

\section{La inteligencia artificial (IA)}

Se suele apuntar como inicio de la IA, la celebración Conferencia de Darmouth, organizada por Minsky, McCarthy y Shanon, en $1956^{13}$. No obstante, hubo importantes avances previos en una primera etapa de configuración de una ciencia dedicada al desarrollo de una inteligencia no biológica y que constituyen las bases de la IA. En 1943, Wiener, Rosenblueth y Bigelow formularon los principios de la cibernética ${ }^{14}$. En 1949, Hebb presentaba un trabajo sobre los mecanismos de aprendizaje, dando vida al paradigma conexionista ${ }^{15}$. En 1950, Turing presenta un test de caracterización basado en la capacidad de replicar el comportamiento humano (test de Turing): 
Disponemos a un humano y una máquina en habitaciones diferentes. Un observador, les hace una serie de preguntas a uno y a otro a través de la puerta. Si pasado un cierto tiempo el observador no es capaz de distinguir quién es el humano y quién la máquina, podemos concluir diciendo que la máquina posee inteligencia. ${ }^{16}$

Dos modelos fundamentales surgieron en esta primera fase de la IA: el simbólico y el neural o conexionista. El primero busca simular las capacidades cognitivas de los seres humanos mediante el procesamiento de fórmulas sintácticas, que reflejan la estructura del lenguaje. El modelo conexionista, en cambio, pretende replicar las operaciones cognitivas a través de la imitación de la actividad inteligente del cerebro y sus conexiones neuronales, elaborando redes de conexiones entre unidades simples ${ }^{17}$.

La teoría conexionista fue cuestionada en 1969 por Minsky y Papert, por la dificultad de que los modelos neuronales pudieran llegar a simular alguna vez habilidades cognitivas mínimamente complejas. A partir de esta crítica, que en ese momento fue considerada insalvable, el estudio de la IA se centró en el modelo simbólico. No obstante, en los años de 1980, el modelo conexionista vuelve a escena, con nuevas teorías que buscan dar explicaciones a las zonas grises del modelo simbolista, retomándose la dualidad simbolismoconexionismo en el desarrollo de la $\mathrm{IA}^{18}$.

En esta progresión, uno de los avances relevantes en inteligencia artificial ha sido el desarrollo de los sistemas expertos, programas informáticos que, a partir de un conocimiento base - proporcionado por la codificación del conocimiento de especialistas en alguna materia-, resuelven problemas de forma rápida y efectiva, emulando a una persona experta en un ámbito concreto ${ }^{19}$. La creación de los sistemas expertos significó un impulso importante a la IA, pues expandió el uso de esta tecnología a múltiples industrias y en diversas funciones, como la atención de clientes, los servicios financieros, las telecomunicaciones, los videojuegos o el derecho.

En la actualidad, la IA está cada vez más presente en nuestras actividades cotidianas, como cuando consultamos en nuestros teléfonos móviles la ruta más corta o el medio de transporte óptimo para llegar a un destino, recibimos correos electrónicos que contienen publicidad relacionada con búsquedas que hemos realizado recientemente en Google, o vamos a un restaurante atendido por robots en China ${ }^{20}$.

Como contrapartida a los innumerables logros en distintas áreas de la IA, todavía hoy su análisis teórico resulta complejo. Como señala Escolano, a pesar de la progresión que se ha mostrado desde su aparición en los años de 1950, sigue pendiente la elaboración de una teoría unificada de la inteligencia y, derivado de ello, de la $\mathrm{IA}^{21}$.

Por tanto, no existe consenso en la comunidad científica sobre un concepto unívoco de inteligencia artificial $^{22}$. Amador señala dos motivos que pueden explicar la dificultad para concordar una definición: "Primero, el continuo recelo y rechazo del hombre a admitir que una máquina pueda incorporar capacidades mentales $[. .$.$] . En segundo lugar, la inteligencia. En sí misma suele ser un concepto mal definido y poco$ comprendido" 23 .

Algunas de las definiciones de IA son: i) "disciplina académica relacionada con la teoría de la computación cuyo objetivo es emular algunas de las facultades intelectuales humanas en sistemas artificiales"24; ii) "ciencia de construir máquinas para que hagan cosas que, si las hicieran los humanos, requerirían inteligencia" 25 .

El objetivo principal de esta disciplina "no son tanto los programas o el propio ordenador sino la conducta inteligente y, en particular, la conducta humana" ${ }^{26}$. Asimismo, Sloman señala que se pueden identificar tres finalidades principales de la IA: (1) el análisis teórico de posibles explicaciones efectivas del comportamiento inteligente; (2) descripción de las habilidades humanas; (3) construcción de artefactos inteligentes ${ }^{27}$.

Podemos ver que, con la IA se estudia, en primer lugar, la inteligencia humana y los procesos cognitivos, intentando descifrar su funcionamiento para, en segundo lugar, aplicar dichos conocimientos al desarrollo de comportamiento inteligente, por medio de unos artefactos creados para dicho fin. 
El estudio de la inteligencia artificial se realiza principalmente desde dos áreas disciplinarias: i) las ciencias cognitivas, que analizan la inteligencia y las funciones cognitivas, y ii) las ciencias formales e ingenierías, centradas en los sistemas lógicos.

Las ciencias cognitivas - filosofía, fisiología, neurociencia, lingüística o psicología, entre otras- estudian la mente, la inteligencia y los procesos cognitivos, relativos a la memoria, el aprendizaje, el lenguaje, o la resolución de problemas, y así determinar si es físicamente posible que una máquina presente capacidad de abstracción similar a la inteligencia humana ${ }^{28}$. Es decir, entregan el marco teórico para que las ciencias técnicas puedan crear máquinas dotadas de IA.

En cambio, las ciencias formales e ingenierías ponen acento en que los problemas no son tanto conceptuales como tecnológicos. El impacto del concepto de IA es indirecto, y lo relevante es que la IA está constituida por cualquier técnica que permita a las personas que trabajan en esta área, sintetizar IA para sus diversos usos. En este sentido, Chrisley coincide con Newell en que existe un sesgo de ingeniería cuando se considera a la filosofía de la mente como un asunto periférico, y que son los avances tecnológicos, y no los desarrollos conceptuales, los que permitieron el avance real de la $\mathrm{IA}^{29}$.

Se centran estas disciplinas técnicas, por tanto, en el desarrollo de tecnología de la IA autónoma, propiamente $\operatorname{tal}^{30}$, restando importancia a los avances en el conocimiento de la inteligencia humana y sus diversas actividades cognitivas.

En estos años ha primado el desarrollo práctico de la tecnología IA. Como expresa Escolano, se ha cedido en la búsqueda de una teoría general de la inteligencia artificial para centrarse en la resolución de problemas concretos, con avances tecnológicos en sistemas inteligentes transferibles fácilmente a la industria, permitiendo el progreso en campos afines — biotecnología, nanotecnología y otras disciplinas- ${ }^{31}$.

En el estado actual de esta tecnología, como advierte la Comisión Europea, la IA ha dejado de ser ciencia ficción para formar parte de nuestras vidas;

Está transformando nuestro mundo, nuestra sociedad y nuestra industria. El crecimiento de la capacidad informática y la disponibilidad de datos, así como los avances en los algoritmos, han convertido la IA en una de las tecnologías más estratégicas del siglo XXI. ${ }^{32}$

Los cambios profundos que estamos viviendo como sociedad, de la mano del desarrollo científico y tecnológico, y especialmente de la IA, están forzando a algunos Estados y organizaciones como la Unión Europea, a asumir un rol activo en la propuesta de un sistema normativo sensible con el estadio actual de desarrollo de la IA. En este marco, los siguientes apartados centrarán en análisis en la IA desde una perspectiva jurídica, apoyándonos en tres casos de estudio.

\section{La inteligencia artificial (IA) y el derecho}

De acuerdo con Casanovas, la inteligencia artificial no tiene por finalidad replicar las funciones cognitivas, tal como el cerebro humano las realiza. En realidad, con la IA se busca entender la estructura y el funcionamiento de estas operaciones —información, memoria, comprensión, entendimiento, lenguaje, expresión y razonamiento-, mejorarlas por procesos computacionales e insertarlas posteriormente en máquinas para su aplicación en contextos reales ${ }^{33}$.

Por otra parte, se nos previene sobre una diferencia fundamental entre la inteligencia humana y la artificial, y que hasta ahora no ha podido ser vencida por la ciencia: "Para alcanzar el nivel de la inteligencia humana, se requiere la propiedad de la autoconsciencia" ${ }^{34}$. Y aunque se han creado estructuras y programas de datos que han avanzado en niveles de autonomía, "todavía las decisiones principales sobre qué hacer se toman por razonamiento lógico, a partir de oraciones presentes explícitamente en la memoria del robot”. Por tanto, la IA no ha logrado aún que sus programas "sean conscientes de sus propios procesos mentales en curso". Cuando 
esto suceda, los dispositivos dotados de IA "alcanzarán el nivel de inteligencia necesario para hacer muchas de las tareas que los humanos querrán darles"35.

El trabajo de McCarthy, considerado el padre de la IA, en realidad apuntaba a la creatividad de las máquinas, avanzar en el desarrollo de un libre albedrío mecánico ${ }^{36}$. De esta forma, y al hilo de la reflexión anterior de Casanovas, esta ciencia no se limita a replicar la inteligencia humana y los procesos cognitivos, sino que pretende producir, en última instancia, máquinas dotadas de autonomía y consciencia. No consciencia humana, sino una desarrollada por la IA, a partir del estudio de nuestra mente.

Estas reflexiones, realizadas desde la ciencia, marcan el punto de inicio de este estudio sobre IA, entendido aquí como una "disciplina tendente a utilizar las tecnologías digitales para crear sistemas capaces de reproducir de forma autónoma las funciones cognitivas humanas, incluida la captación de datos y formas de comprensión y adaptación (solución de problemas, razonamiento y aprendizaje automáticos)”37.

El desarrollo exponencial que está teniendo la IA, expandida a casi todos los ámbitos de nuestra vida ordinaria — no solo para actividades complejas y especializadas, como la medicina, la nanotecnología o la robótica, sino también a situaciones cotidianas, como conducir un automóvil o utilizar el teléfono móvil —, está generando incertidumbre y riesgos; características de nuestra época tecnológica ${ }^{38}$. La búsqueda de una inteligencia no biológica, que pueda superar las funciones cognitivas del cerebro humano, para poder desarrollar tareas que requieren de algún tipo de operaciones cognitivas, abre la puerta a nuevas relaciones jurídicas, no concebidas en los sistemas normativos vigentes.

En este sentido, la posibilidad cada vez más real de disponer de máquinas provistas de niveles avanzados de autonomía y consciencia constituye el desafío filosófico jurídico de fondo que la inteligencia artificial plantea al derecho. Cómo se aborda, desde la teoría del derecho, la integración de máquinas con una inteligencia igual o superior a la humana y dotadas de algunas propiedades de autonomía y autoconsciencia, que les permite tomar, en determinadas circunstancias, decisiones independientes, con consecuencias jurídicas.

Tal como sucede con la IA, en la que el avance tecnológico casuístico se ha impuesto al análisis teórico, también en el Derecho ha habido un acercamiento a la inteligencia artificial, desde una perspectiva práctica, antes de realizar disquisiciones relativas a una teoría del derecho para la IA.

De esta forma, los diversos problemas de carácter jurídico, que se han ido presentando con la expansión de la IA, han comenzado a ser resueltas de una forma pragmática, desde las distintas áreas del ordenamiento jurídico - civil, penal, laboral, ambiental, etc.—, atendiendo a un criterio de especialidad. No se ha logrado todavía mostrar un proceso de sistematización en torno a la relación derecho-IA, que apunten a una teoría general del derecho ante la inteligencia artificial, con principios, criterios y normas propias ${ }^{39}$.

Sin embargo, incluso esta solución funcional resulta compleja ante la disrupción tecnológica que estamos viviendo ${ }^{40}$. Las respuestas de un derecho dúctil, flexible, pragmático, a los problemas que está generando el uso masivo de la IA, están dando lugar a una importante casuística que marca cada vez más distancia con las normas. De esta forma, la obsolescencia normativa que se está produciendo naturalmente con la IA, se ve acentuada por una interpretación extensiva, realizada por los jueces, en la resolución de los casos que conocen.

En este contexto, el cambio tecnológico nos presenta el desafío de cómo abordar la cuestión de la IA desde el derecho. Aunque, a primera vista, Bennet señala, resulta lógico proponer una teoría general del derecho para los temas relativos a la tecnología, la cuestión en realidad no es de tan fácil solución. Por una parte, cabe advertir que el desarrollo técnico, en general - y la IA en particular-, incluye problemáticas tan disímiles como las que plantea el uso de bases de datos para predecir o inducir conductas de las personas, la telemedicina o la nanotecnología. Y, por otra, se corre el riesgo de deificar la tecnología, situación que puede dar como resultado la dificultad para que el legislador pueda poner supuestos de prohibición de desarrollo de IA ${ }^{41}$.

$\mathrm{Si}$, en cambio, optamos por primar un desarrollo normativo casuístico, a medida que se vayan presentando los problemas jurídicos relativos a la utilización de la IA, estaríamos eternizando la cuestión antes planteada, 
relativa a la permanente carrera en que parecen estar el cambio tecnológico y el derecho, en el que este último, se presenta como el gran derrotado.

Por tanto, la solución que adoptemos para abordar, desde una perspectiva jurídica, el mundo que se nos presenta con la IA no es baladí ${ }^{42}$. Aun cuando parece imponerse el avance pragmático de normas de derecho civil, penal, laboral, etc., con contenido referido a la inteligencia artificial, estimamos que debe avanzarse en ambos sentidos.

La conexión regulatoria entre la norma y el cambio tecnológico, centrado en este caso por la IA, ${ }^{43}$ debe ser abordada en las dos dimensiones descritas. Por una parte, deben forjarse cambios normativos sectoriales para dar respuesta a los diversos problemas que van surgiendo a medida que la IA se va expandiendo. De esta forma, el sistema jurídico va adaptándose progresivamente al nuevo mundo. Y, por otra, se debe reflexionar desde la teoría del derecho, sobre la inteligencia artificial, a fin de identificar principios, criterios y normas que doten de flexibilidad al sistema jurídico, y que sirvan de marco general al desarrollo normativo que la IA requiere.

Esta es la posición que parece haber adoptado la Unión Europea en su Comunicación sobre inteligencia artificial, de $2018^{44}$. Por una parte, insta a avanzar en una política europea para la IA, que incluya nuevas normas de derecho civil, laboral, etc., que se adecuen a las transformaciones socioeconómicas que origina la IA. Por otra, incentiva a los Estados miembro a "garantizar el establecimiento de un marco ético y jurídico apropiado, basado en los valores de la UE y en consonancia con la Carta de los Derechos Fundamentales de la UE" ${ }^{\prime 5}$.

Como puede verse, la Unión Europea pone en relieve uno de los grandes retos que enfrenta el derecho, cuando hablamos de IA: la adaptación de los derechos fundamentales, tanto en su dimensión teórica como práctica, ante el proceso de digitalización y automatización a que nos ha abocado la disrupción tecnológica que estamos viviendo. En los siguientes apartados abordaremos esta cuestión como parte de los problemas y desafíos que enfrenta el derecho ante el avance de la IA.

\section{Problemas derivados del uso de la inteligencia artificial (IA)}

Como hemos señalado, la IA ha traído múltiples beneficios, en distintos ámbitos de nuestra vida. Entre estas, destacan las diversas aplicaciones en medicina, la mejora de la eficiencia de los sistemas de producción en general, la contribución a la mitigación del cambio global, o el aumento de la seguridad de las personas ${ }^{46}$. De esta forma, la IA —incluida la IA incorporada en robótica y técnicas del aprendizaje automático- está aumentando los estándares de nuestro bienestar social y económico, y ayudando en el ejercicio de los derechos humanos, dando lugar a una mayor calidad de vida de las personas ${ }^{47}$.

No obstante, tal como sucede con cualquier otra herramienta o tecnología, la IA conlleva una serie de riesgos potenciales, como la opacidad en los procesos de toma de decisiones, el sesgo y las discriminaciones de todo tipo, la intromisión en nuestras vidas privadas, o su uso con fines delictivos ${ }^{48}$. De la misma manera, los artefactos con IA, a medida que avanza su autonomía, podrían tener comportamientos impredecibles o potencialmente dañinos ${ }^{49}$.

En este sentido, Verheij señala que los distintos campos de investigación en IA tienen tres desafíos comunes para disminuir los riesgos que tiene su desarrollo : (i) la IA debe ser social, permitiendo una interacción sensata con los humanos; ii) la IA debería ser explicable, de manera que los algoritmos entrenados en datos se vuelvan transparentes al proporcionar explicaciones justificadas, y iii) la IA debe ser responsable; es decir, guiarse por las reglas, normas y leyes de la sociedad ${ }^{50}$.

Como suele suceder con las nuevas industrias, que desarrollan productos o servicios que antes no existían y que rápidamente pasan a ser esenciales para la sociedad, en una primera etapa su funcionamiento es entregado a la autorregulación de la actividad. Cuando aparecen los primeros problemas de naturaleza jurídica, que no 
pueden ser corregidos con las reglas de comportamiento que se ha dado el propio sector, los países buscan en la legislación vigente soluciones creadas para situaciones análogas. $Y$ una vez que las nuevas relaciones jurídicas desbordan el marco normativo existente, se inicia un proceso de regulación de la actividad, con nuevas normas y también una nueva institucionalidad, incluidos órganos reguladores especializados ${ }^{51}$.

Es la etapa en que nos encontramos actualmente. La autorregulación de la actividad y la adaptación del marco normativo existente a las nuevas cuestiones jurídicas que propone la IA, principalmente a través de la labor jurisdiccional, comienza a dar paso a un proceso de regulación de su industria. Diversas instancias internacionales y nacionales han comenzado a surgir para diseñar una institucionalidad y legislación marco, que permita desarrollar una regulación de la actividad relacionada con la IA, con normas adecuadas para resolver los problemas jurídicos que se vienen planteando, moderar su impredecibilidad, morigerar los riesgos asociados, y proyectar su desarrollo futuro ${ }^{52}$.

A continuación, revisaremos los principales problemas a que nos hemos enfrentado en el tráfico jurídico con el uso cada vez más intenso de la tecnología IA. El ejercicio se hará por medio de tres ejemplos prácticos.

\section{El despido de una trabajadora para ser sustituida por un robot}

En septiembre de 2019, la prensa española daba cuenta de una innovadora sentencia dictada por el Juzgado de lo Social número 10 de Las Palmas de Gran Canaria. Declaraba improcedente el despido de una administrativa contable que había sido reemplazada por un robot. La trabajadora prestaba servicios a la empresa desde 2006, hasta que esta adquirió en 2019 la licencia de Jidoka, un Robotic Process Automation (RPA), momento en que la despide ${ }^{53}$.

La trabajadora estima que el despido era improcedente, por lo que interpone una demanda laboral, dando lugar al juicio sobre despido $\mathrm{No}$ 470/2019. El principal argumento de la actora es que los hechos contemplados en la carta de despido no son ciertos, y que la situación productiva de la empresa se basa en previsiones o suposiciones no constatadas al tiempo del despido. La demandada sostiene la veracidad de los datos contenidos en la carta y, por ende, la procedencia del despido objetivo, por causas productivas, técnicas y organizativas (fundamento de derecho $2^{\circ}$ de la sentencia).

El tribunal fundó su sentencia en que las causas productivas, técnicas y organizativas alegadas por el demandado no fueron probadas para resolver la improcedencia del despido y obligar al empleador a optar entre la readmisión de la actora, o pagar una indemnización que estima en $€ 28.305,49^{54}$.

En lo que aquí interesa, la resolución realiza unas reflexiones interesantes, referidas a la automatización del trabajo como causal objetiva de despido, que se exponen a continuación. En primer lugar, la sentencia hace referencia a las razones estrictamente económicas que llevaron al despido. Señala que "los costes asociados a la implantación del RPA (licencia de servidor, nodo de producción y configuración) ascienden a un total de 12.900 euros anuales, en tanto que el coste de mantenimiento del puesto de trabajo de la actora representa para la Empresa 28.412,44 euros anuales" (fundamento de derecho quinto). Además "el 'bot' trabaja de 17:30 a 06:00 horas entre semana (12 horas y media) y 24 horas los fines de semana y festivos" 55 . Teniendo esto en cuenta — razona el tribunal - el 'bot' trabaja 392 horas mensuales por $€ 12.900$ anuales, mientras que la actora lo hace 160 horas al mes, por $€ 28.412,44$ anuales. Es decir, que el 'bot' realiza el trabajo de 2,5 personas, y a un coste inferior a la mitad de los tres trabajadores despedidos con la adquisición del RPA —la demandante y otros dos trabajadores cesados con ella- (fundamento de derecho quinto).

Sin embargo, el Tribunal da por no acreditado la mejora de eficiencia con la automatización, alegada por la demandada. Es decir, aun cuando se señala que la actora destinaba 15 minutos para la atención de un cliente, en las labores de su responsabilidad, que con el sistema de RPA esa actividad se realizará en 55 segundos, y una empresa externa acreditó que ello era razonable, el tribunal exigió que la prueba pericial diera fe de la efectividad de esa eficiencia, y no de su razonabilidad en abstracto. 
Otro argumento que esgrime el tribunal para rechazar el despido por las causas productivas, técnicas y organizativas alegadas, es que el software no realizaba las mismas funciones que la actora. De los quinientos clientes que llevaba esta, el RPA atendería solo a siete, los que más facturaban. Y tampoco asumía el 100\% de las tareas relacionadas con dichos clientes prioritarios, sino que el $70 \%$ de ellas. Y con todo, ello tampoco estaba acreditado de manera fehaciente.

Finalmente, y creemos lo más relevante de la sentencia, el Tribunal hace una valoración en torno a los dos derechos fundamentales que entrarían en colisión en esta causa, y en la generalidad de los casos en que la automatización de las funciones y los procesos signifique el despido de trabajadores: la libertad de empresa y el derecho al trabajo. Al ser ambos "dignos por igual de protección jurídica", para determinar el interés prevalente, debe recurrirse a un juicio de proporcionalidad (fundamento de derecho sexto).

Y en el examen de ponderación que realiza el tribunal, señala que, encima de la libertad de empresa y el derecho al trabajo, se encuentra "el interés público en el mantenimiento del empleo", que nace de la esencia misma del Estado social, que reconoce derechos y entrega una serie de garantías. En este sentido, "la automatización de labores repetitivas que no ofrece un valor añadido" supera a la libertad de empresa, alcanzando la estabilidad del empleo en su conjunto (fundamento de derecho sexto).

En el mismo fundamento sexto, la resolución explica que la automatización del trabajo a 2035 crecerá en orden a $77 \%$ en China, $69 \%$ en India, $47 \%$ en Estados Unidos y $43 \%$ en España. De esta forma, la automatización de los procesos significará una destrucción de empleo superior al 35\% de la población activa, y en gran parte el reemplazo no conlleva un plus de innovación para las empresas, sino que se limita a la mera optimización de costes.

Con la automatización tampoco opera un cambio de medios o instrumentos de producción, como sucedió con el paso de las cámaras fotográficas analógicas a la digital, que llevó a la desaparición de actividades relacionadas - fotógrafo manual, técnico de revelado, etc.-. Con la automatización se produce la sustitución de un trabajador por un instrumento, que además realiza tareas repetitivas y sencillas (fundamento de derecho sexto).

En consecuencia, cuando chocan los derechos relativos a la libertad de la empresa y el derecho al trabajo, además de tener en consideración el interés público en el mantenimiento del empleo, debe estimarse que el despido objetivo - fundamentado en causas productiva, técnicas y organizativas, que reduce el monto de la indemnización y facilita el despido-, no puede amparar el aumento de la competitividad de la empresa, fundada exclusivamente en el reemplazo del trabajador.

En este sentido — volviendo a la sentencia-, de permitirse el despido de un trabajador motivado exclusivamente en el reemplazo por una máquina o un software,

se erige la mejora de la competitividad como elemento único que justifique el despido, mediante la introducción de "bots" que automaticen el trabajo, desplazando a la masa laboral humana. Definitivamente, esto no puede ser tenido en cuenta como una causa justa para un despido objetivo procedente, por cuanto lo contrario implicaría favorecer, so pretexto de la competitividad, la subestimación y minimización del derecho al trabajo (fundamento de derecho sexto).

Como vemos, la destrucción de empleo, con la automatización de las funciones administrativas y los procesos industriales realizados por robots y software, es uno de los principales problemas que la IA está generando. En este sentido, el Parlamento Europeo, en Resolución de 2017, expresó su preocupación sobre la evolución del trabajo a medio y largo plazo, poniendo especial atención en la deslocalización y pérdida de puestos de trabajo como consecuencia de la mayor utilización de robots ${ }^{56}$.

De la misma manera, el Comité Económico y Social Europeo insta a que los procesos de transformación económica, derivados de la IA y sus efectos en el empleo y el trabajo, sean socialmente sostenibles ${ }^{57}$. Una de las características de la IA es que nos trae incertidumbre, y esto se traslada también a la evolución del empleo y las características del trabajo en el futuro. 


\section{El uso de bots en redes sociales puede influir en los resultados de procesos eleccionarios y en las crisis sociales de los países}

En 2018, la prensa mundial daba cuenta de un estudio que afirmaba que "los 'bots"'58 de Twitter influyeron en los resultados del Referendo del Brexit y las elecciones presidenciales de EE.UU., ambas de 2016. De esta forma, las cuentas automatizadas de esta red social habrían desempeñado un papel importante en estos dos procesos electorales, que dieron la victoria por estrecho margen a la opción de que Reino Unido abandonase la Unión Europea, y a Donald Trump, respectivamente 59 .

El estudio de Gorodnichenko, Pham y Talavera comenzaba resaltando que el auge de internet ha cambiado la manera en que nos comunicamos e informamos. El consumo de los medios de comunicación tradicionales ha disminuido, y las redes sociales se han convertido en una fuente de información cada vez más importante para muchas personas. Estas dan acceso instantáneo y abierto a noticias y narrativas, permitiendo además opinar de manera instantánea, lo que implica una verdadera revolución en el ámbito de las comunicaciones ${ }^{60}$.

En este contexto, el estudio buscaba responder a la pregunta de cómo esta nueva forma de comunicarnos ha influido en los flujos de información entre las personas y cómo se puede influir en esos flujos. El caso práctico utilizado para el análisis son estos dos procesos electorales que tuvieron un perfil extremadamente alto Brexit y elección presidenciales EE.UU. 2016- Se revisaron dos tipos de agentes de redes sociales: personas humanas y bots sociales; estos últimos son "algoritmos informáticos utilizados para producir contenido automatizado". Asimismo, el trabajo se centró en Twitter, que en 2016 contaba con unos 15,8 millones de usuarios en Reino Unido y 67 millones en EE.UU. ${ }^{61}$

En el caso de las elecciones de EE.UU. 2016, la particular campaña electoral de Donald Trump hizo muy visible un cambio en las dinámicas tradicionales de cómo se llevaban a cabo las campañas en democracias occidentales.

Ciertos límites que antes eran claros eran ahora difíciles de determinar; por ejemplo, saber quiénes son parte de la campaña y quienes no [...]. También se pudo evidenciar el uso estratégico de la generación de tuits para determinar la agenda de los medios tradicionales; cuando el candidato tenía menos cobertura tuiteaba en mayor cantidad que cuando recibía mayor cobertura. ${ }^{62}$

Así, la campaña digital de 2016 ha sido muy diferente a lo conocido, y obligó a repensar las campañas electorales futuras, de cualquier país. La mayor parte de la historia de las elecciones de 2016 gira en torno a la explosión en línea de la comunicación relevante para la campaña desde todos los rincones del ciberespacio ${ }^{63}$.

Un ejemplo de esto lo presentan Howard, Woolley y Calo, en los momentos en que Trump más necesitaba del apoyo latino, aparecieron seguidores con nombres como "Pepe Luis López, Francisco Palma o Alberto Contreras, que tuiteaban en favor del candidato. El problema es que estos no eran votantes, ni son personas reales, eran bots diseñados para hacerse pasar por votantes latinos en un momento en que Trump más los necesitaba" 64

El estudio de Gorodnichenko, Pham y Talavera concluyó que el uso de bots en Twitter para difundir y amplificar mensajes en un sentido u otro, a modo de información, había influido en las personas, especialmente en las que tienen ideas afines y que, por tanto, pudieron servir para "dinamizar a los votantes, influyendo marginalmente en los resultados de ambos procesos eleccionarios" ${ }^{65}$. De esta forma, los autores señalan que las acciones de tuits pro Trump sugieren que el 3,23\% de los votos reales podrían racionalizarse con la influencia de los bots. De la misma manera, en el caso del Brexit, este porcentaje se sitúa en el 1,76\% de la participación real en el voto a favor de la salida de la UE. Ello es relevante, si tenemos en consideración los porcentajes de diferencia de las opciones ganadoras y perdedoras fue mínima, y por tanto, la actividad de los bots pudo ser determinante en los resultados de ambos procesos ${ }^{66}$.

En este sentido, Santana y Huerta expresan: 
Parece ser que ciertas dinámicas que suceden en las redes sociales, tanto a partir de las características no digitales de los individuos, como de las características cambiantes de las plataformas, son propicias para generar condiciones que cambian la forma y distorsionan la legitimidad de la participación y el debate público, aumentando la vulnerabilidad de la democracia en occidente. ${ }^{67}$

Veamos ahora un caso de uso de bots y redes sociales en el contexto de una crisis social. Nos situamos en el estallido social chileno, iniciado el 18 de octubre de $2019^{68}$. En el contexto de los graves incidentes que estaban teniendo lugar, el Ministerio del Interior anunciaba, el 19 de diciembre de 2019, que había entregado al Ministerio Público un informe de 112 páginas, en que se resume el comportamiento de las redes sociales durante el estallido social ${ }^{69}$. En este, señaló el ministro del Interior, Gonzalo Blumel, existía "información extraordinariamente sofisticada a partir de análisis de big data, con tecnologías de la información, que dan cuenta de antecedentes que son importantes para la investigación penal", refiriéndose a las causas abiertas por el Ministerio Público, ante los graves incidentes, que incluía el incendio de autobuses, edificios, hoteles, iglesias, saqueos a supermercados y locales comerciales, pero especialmente por la destrucción de 78 estaciones de metro en un espacio de tiempo de 48 horas, en Santiago, en los primeros días de la crisis social ${ }^{70}$. En dicho informe, según el Ministerio del Interior chileno, se analizaron sesenta millones de comentarios, publicados en Twitter por cinco millones de usuarios, muchos de ellos de cuentas extranjeras. Asimismo, el informe destacaba que había identificado la participación de más de 11.000 usuarios considerados bots o usuarios con actividad anómala, cuyas cuentas fueron creadas después de 18 de octubre de 2019, es decir, una vez iniciadas las protestas sociales. Por este motivo, el gobierno chileno propuso una teoría conspirativa para la crisis social, organizada por grupos antisistema, radicales y apoyados por terceros países, como Venezuela o Cuba, y presentaba el informe como prueba de ello.

Sin embargo, el fiscal Nacional rápidamente ponía en duda la seriedad de este informe, señalando que no se trataba de un informe de inteligencia, sino de un informe de fuentes abiertas, y fundado en el análisis de redes sociales y de la prensa nacional y extranjera. Asimismo, expresaba no haber encontrado "ningún valor en la información que contenía", y que aportaba pocos antecedentes que pudieran "hacer valer en juicio"71.

Este caso nos presenta un problema complejo, derivado del uso de las redes sociales y la tecnología IA, para convocar, organizar, promover o dirigir crisis sociales, pero también como herramienta para investigaciones de los gobiernos que, a través de análisis de big data, y justificados en razones de seguridad y orden público, juegan en las fronteras de la libertad de expresión de las personas y el derecho a la protesta pacífica.

Un último ejemplo sobre la incidencia de la IA en las nuevas formas de ejercicio de derechos relacionados con la democracia. El 20 de abril de 2020, la prensa española se hacía eco de una denuncia del gobierno de Pedro Sánchez, que afirmaba ser víctima de una actividad fraudulenta de bots que viralizaban las publicaciones de Sanidad en Facebook ${ }^{72}$. Ello en plena crisis sanitaria de España que ha costado la vida a varias decenas de miles de personas en el país. El ataque cibernético consistía en "difundir los mensajes del Ministerio de Sanidad y elogiar la gestión del Gobierno" a través de cuentas falsas de Facebook. Se trataría de un "ataque de falsa bandera (procedente de sus rivales políticos, para incriminar a los socialistas en la creación de perfiles falsos)" ${ }^{\prime 3}$. En este caso, los bots de redes sociales han sido utilizados, supuestamente, para desestabilizar un gobierno, en momentos en que está siendo fuertemente cuestionado por su manejo en una crisis sanitaria grave, como la que estamos viviendo con la covid-19. De esta forma, se lograría crear una opinión pública adversa al gobierno, como respuesta a las congratulaciones que bots, simulando ser adherentes, hacen de la acción del gobierno ante la crisis social.

Como puede observarse en estos ejemplos, el objetivo del uso de bots en redes sociales, durante las campañas electorales es influir en el electorado, entregando información - verdadera o falsa- que parece relevante en clave política. Tal como advierten Gorodnichenko, Pham y Talavera, el uso de bots en redes sociales, especialmente en Twitter, puede crear una sensación de consenso y apoyo público, afectando las opiniones públicas de nuevas maneras ${ }^{74}$. 
Asimismo, en el caso de las crisis sociales - y sanitarias-, las redes sociales y los bots pueden ser usados para desestabilizar a un Gobierno, a fin de lograr su caída. De la misma manera, pueden ser utilizados por los gobiernos para justificar labores de inteligencia policial en las actividades de los ciudadanos en las redes sociales, debilitando el contenido de los derechos fundamentales de naturaleza política.

En cualquier caso, estamos hablando de un cambio en el ejercicio de los derechos y deberes relacionados con la democracia.

[La actual] infraestructura tecno-social que permiten las tecnologías digitales recibe, además de los actores ya conocidos, el intercambio de ciudadanos individuales e incluso agentes anónimos que se conectan e intercambian contenidos entre ellos, generando una esfera pública híbrida en red, en parte digital y en parte análoga. Esta nueva esfera pública ha facilitado la circulación de ideas políticas públicas, y por lo tanto influye en la opinión pública y en los resultados de ciertos procesos políticos. ${ }^{75}$

Si a esto sumamos que la IA nos permite enviar de manera masiva y reiterativa mensajes en redes sociales, por medio de "cuentas de spam que publican de forma autónomo utilizando scripts preprogramado" ${ }^{\text {" } 76 \text { los }}$ bots-, la probabilidad de influir en la opinión pública por medios no convencionales es mayor.

Evidentemente, el fenómeno de buscar manipular la opinión pública para fines políticos no es nueva. Lo novedoso es que las redes sociales permitan el diálogo de personas con "fragmentos de códigos fugaces conocidos como bots", y, por tanto, algunas de las personalidades que nos encontramos en el ciberespacio, con quienes debatimos y con quienes estamos de acuerdo o en desacuerdo, no son quiénes o qué pretenden $\operatorname{ser}^{77}$.

Esta nueva situación está generando dificultades a los sistemas electorales y sus legislaciones, así como a las formas de participación política de los ciudadanos, al ejercicio de los derechos fundamentales - como la libertad de expresión o el derecho a la protesta pacífica一, y a los límites de las campañas políticas. La democracia y su régimen jurídico también deben adaptarse a la revolución tecnológica en marcha.

\section{Un vehículo autónomo atropella a una persona, con resultado de muerte}

El 19 de marzo de 2018 un accidente automovilístico llamó la atención de la comunidad mundial. Era protagonizado por un coche autónomo operado por Uber y una mujer que cruzaba una carretera de Tempe, fuera del paso de peatones. El vehículo circulaba en modo autónomo, sin conductor, aunque había una persona en su interior tras el volante. La mujer, que caminaba junto a su bicicleta, fue atropellada por el automóvil que circulaba de manera autónoma, con resultado de muerte. Después de este lamentable accidente, Uber anunciaba que suspendía las pruebas de sus vehículos sin conductor en EE.UU. ${ }^{78}$ No obstante, resulta lógico pensar que estas pruebas igual continuarán en un futuro próximo.

El hecho de que la víctima haya cruzado la carretera lejos de un paso de peatones facilita en parte la reflexión que se pueda hacer sobre la responsabilidad penal y civil. Pero ¿qué hubiera pasado si la persona hubiese sido atropellada por el coche autónomo en el paso de peatones?

De acuerdo con Elizalde, si proyectamos un parque automotriz integrado solo por vehículos autónomos, estaríamos en un escenario en que se asume que "todos los accidentes que ocurran serán consecuencia de un defecto del producto o de un defecto en la infraestructura vial”. Si nos centramos en el defecto del producto, la autora explica que:

Se presume que la tecnología es perfecta y que debería detectar, prever y evitar cualquier accidente. Consecuencialmente, en caso de producirse un accidente, el único responsable del accidente sería el fabricante al considerar que el vehículo autónomo es defectuoso por no haber detectado, previsto y evitado la causa del accidente. ${ }^{79}$

Como vemos, la IA nos permite pensar en una realidad de vehículos autónomos ${ }^{80}$. Ello nos llevará a que las reglas de la responsabilidad civil del conductor y propietario se desplacen a un sistema de responsabilidad centrada en dos supuestos básicos: i) la responsabilidad del fabricante de vehículos autónomos, por defecto en 
el vehículo, y ii) la responsabilidad de la Administración Pública por defectos de la infraestructura vial ${ }^{81}$.Junto con esto, habrá que elaborar nuevas acciones, reglas y procedimientos para determinar la responsabilidad para casos de accidentes de circulación; también nuevos sistemas de seguros para esta categoría de vehículos. Asimismo, se profundizará en las reglas sobre la responsabilidad del fabricante del vehículo y del desarrollador del software ${ }^{82}$.

Podemos observar que el tema de fondo para este caso expuesto es la responsabilidad. Esta temática es una de las que mayor interés ha concitado por la doctrina y el legislador, en torno a la IA, por su relevancia ${ }^{83}$. Debe observarse, en este sentido, que el derecho civil en general y el régimen relativo a la responsabilidad civil en particular, se caracterizan por la naturaleza especialmente abierta y abstracta de sus normas y, por tanto, flexible, que les ha permitido una adaptación aceptable a los problemas que se han generado en torno a la responsabilidad derivada del uso de la IA.

De esta forma, por ejemplo, la teoría del producto defectuoso y la consecuente responsabilidad del fabricante, que han acogido la mayoría de los ordenamientos, han dado respuesta a gran parte de los supuestos en los que las máquinas dotadas de IA han dado lugar a hechos en que se han producido daños ${ }^{84}$. No obstante, debe reconocerse también que la IA ha impactado estructuralmente en el derecho y que también el derecho civil debe sumarse a la reflexión general que se ha iniciado sobre la relación derecho-IA.

En este sentido, una de las modificaciones de fondo de los regímenes jurídicos relativos a la responsabilidad, cuando hablamos de IA, está referida a la posibilidad de dotar de algunos atributos de la personalidad a robots, cuando estos tomen decisiones autónomas inteligentes ${ }^{85}$. Sobre esta idea, profundizaremos en el siguiente apartado.

En relación con la responsabilidad y la IA, el Parlamento Europeo advierte que

Considerando que, gracias a los impresionantes avances tecnológicos de la última década, los robots ya no solo pueden realizar actividades que antes eran típica y exclusivamente humanas, sino que el desarrollo de determinados rasgos cognitivos y autónomos - como la capacidad de aprender de la experiencia y tomar decisiones cuasi independientes - ha hecho que estos robots se asimilen cada vez más a agentes que interactúan con su entorno y pueden modificarlo de forma significativa; que, en este contexto, es crucial la cuestión de la responsabilidad jurídica por los daños que pueda ocasionar la actuación de los robot. ${ }^{86}$

La IA ha cambiado la actitud hacia el intelecto, que hasta hace poco se consideró una característica exclusiva de los seres biológicos. Si bien la idea de unos sistemas artificiales que piensan y actúan racionalmente siempre fue el objetivo inicial de la IA, esto era visto como ciencia ficción. Hasta que los avances tecnológicos comenzaron a dar mayor autonomía y se avanzó en dotar de ciertos niveles de consciencia a las máquinas ${ }^{87}$.

Estos progresos han permitido que estos sistemas puedan entrenarse a sí mismos, permitiendo a la IA actuar de manera diferente en las mismas situaciones. La capacidad de acumular experiencia y aprender de ella, actuar de manera independiente y tomar decisiones independientes crea condiciones previas para el daño. De esta forma, con sus acciones, la IA puede causar daño y ello debe ser resuelto con los ordenamientos vigentes. Pero de nuevo volvemos a la idea que en el esquema normativo de responsabilidad actual, los responsables de este tipo de daño somos, en última instancia, las personas ${ }^{88}$. Y sobre ello, debe reflexionarse desde la teoría del derecho.

Como vemos, los problemas que nacen con el desarrollo de IA autónoma y con niveles avanzado de algún tipo de consciencia obligan a revisar el régimen jurídico sobre responsabilidad de los países, para poder responder de manera clara a supuestos en que los problemas no se generan entre personas, naturales o jurídicas, sino que involucran a máquinas dotadas de IA. Aun cuando el régimen vigente ha salvado la situación, remitiendo a la responsabilidad del creador del software, esta solución resulta cada vez más difícil de sostener, en la medida que interactuamos con tecnología avanzada de IA, donde las máquinas, aprenden de sus errores y, por tanto, comienzan a actuar de manera impredecible y, como consecuencia, a generar riesgos para las personas. 


\section{Desafíos para el derecho ante el avance de la inteligencia artificial (IA)}

Los riesgos relacionados con la IA han sido observados primero como dilemas éticos, antes de ser pensados desde una perspectiva jurídica. Se parte del supuesto de que la tecnología IA no ha logrado niveles avanzados de autonomía y consciencia, y, por tanto, es éticamente neutra. De esta forma, su eventual uso malicioso dependería de la voluntad de las personas que la manipulan, del error humano o de un defecto de producción.

Sin embargo, el aumento de controversias de naturaleza jurídica, en la medida que se avanza en los niveles de autonomía y consciencia de la IA, ha trasladado la preocupación hacia la esfera del derecho, dejando de ser observados — los problemas derivados del uso de IA —, como una cuestión puramente ética ${ }^{89}$.

Esta visión ha primado en las primeras reuniones que han sostenido la Unión Europea, EE.UU. y Reino Unido, a partir de octubre de 2016, para acordar una legislación marco, bajo unos principios éticos universales, que rijan las actividades relacionadas con la IA, entre ellas la legislativa. La idea central de los documentos elaborados a partir de estas reuniones de trabajo es que debe generarse un entorno amigable para la $\mathrm{IA}^{90}$.

De esta forma, la identificación de principios y valores éticos sobre IA constituye la base de una incipiente "buena sociedad de inteligencia artificial", que incluye políticas públicas, desarrollo regulatorio, y una gobernanza que incluya la colaboración del sector privado y la comunidad científica ${ }^{91}$.

En este sentido, el Parlamento Europeo, en su propuesta de legislación sobre desarrollo, despliegue y uso de IA, robótica y tecnologías asociadas, de 2020, ha identificado los principios éticos que deben guiar a un marco jurídico de referencia para la IA, como se puede observar en el artículo 4 de la propuesta legislativa, antes de comenzar con el diseño legislativo en los países miembros. Estos son los siguientes:

Toda IA, robótica y tecnologías relacionadas, incluidos el software, los algoritmos y los datos utilizados o producidos por dichas tecnologías, se desarrollarán, implementarán y utilizarán de conformidad con los principios éticos;

El desarrollo despliegue y uso de la IA, robótica y tecnología relacionadas, se llevarán a cabo de manera que garantice la dignidad humana y los derechos fundamentales de las personas;

El desarrollo despliegue y uso de la IA, robótica y tecnología relacionadas, se llevarán a cabo en el mejor interés de los ciudadanos, protegiendo y fomentando el bienestar social, ambiental y económico de la sociedad $^{92}$.

Al hilo de estos principios éticos, abordaremos los principales desafíos que la IA plantea al derecho.

\section{Desarrollo de una regulación para la IA}

Siguiendo las ideas que se han ido desarrollando en los apartados anteriores, el primer desafío es de naturaleza normativa. Se hace necesario elaborar normas que respondan a las relaciones jurídicas propias de la sociedad tecnológica que hemos construido.

Este desarrollo, de una regulación para la IA, debe abordarse en una doble dimensión. En primer lugar, es necesario desarrollar un marco jurídico general que oriente el diseño de toda la legislación específica para la actividad relativa a la IA. De acuerdo con la Comisión Europea, para abordar los retos y aprovechar las oportunidades que ofrece la IA debe avanzarse en un marco jurídico apropiado, centrado en el ser humano, que potencie la capacidad tecnológica e industrial de los países y que impulse la adopción de la IA en todos los ámbitos de la economía ${ }^{93}$.

Como vemos, subyace bajo esta idea, la necesidad de reflexionar en torno a una teoría jurídica para la IA, que permita una adaptación del derecho, sustantiva y formal, a los desafíos que propone la sociedad tecnológica, que convive con la IA. 
Este marco jurídico base, integrado por principios, legislación básica y normas especiales de naturaleza sectorial, debe tener por finalidad el desarrollo de una IA fiable, que genere un entorno adecuado para la innovación en IA y su uso provechoso. Para que ello sea posible, deben impulsarse mecanismos de gobernanza con enfoque en la participación humana (buman-in-the-loop), la supervisión humana (buman-on-the-loop), o el control humano (buman in-command). De esta forma, el ordenamiento debe dotar de competencia a los órganos generales de la Administración Pública y crear órganos e instrumentos para la supervisión de la actividad relacionada con la $\mathrm{IA}^{94}$.

Asimismo, el Parlamento Europeo señala que la regulación de la IA debe tener en cuenta las siguientes orientaciones: (i) los problemas y riesgos derivados del uso de la IA deben ser evaluados detenidamente a la luz de la seguridad y la salud humana; la libertad, la intimidad, la integridad y la dignidad; la autodeterminación y la no discriminación, y la protección de los datos personales; (ii) los marcos normativos deben actualizarse y complementarse por medio de directrices éticas que reflejen la complejidad de la robótica y sus implicaciones sociales, médicas y bioéticas. De la misma manera, un marco ético claro debe orientar el desarrollo, diseño, uso y modificación de los robots; (iii) igualmente, debe atenderse al principio de transparencia, en cuya virtud siempre ha de ser posible justificar cualquier decisión que se haya adoptado con ayuda de la IA y que pueda tener un impacto significativo sobre la vida de las personas. En este sentido, siempre debe ser posible reducir los cálculos del sistema de IA a una forma comprensible para los humanos, los robots avanzados deberían estar siempre equipados con una caja negra que registre los datos de todas las operaciones realizadas por la máquina, incluidos los pasos lógicos que han conducido a la formulación de sus decisiones; (iv) que el marco de orientaciones éticas del ordenamiento jurídico debe basarse en los principios de beneficencia, no maleficencia, autonomía y justicia, respeto a los valores, principios y derechos de los sistemas internacionales de derechos humanos, la responsabilidad individual y la responsabilidad social; (v) se debe prestar especial atención a la IA que representa una amenaza significativa para la privacidad, debido a su ubicación en espacios tradicionalmente protegidos y privados, y a su capacidad de obtener y transmitir información y datos personales y sensibles ${ }^{95}$.

Como vemos, se trata de un conjunto de principios que sirven de nexo entre lo ético y lo jurídico, y que deben ser tenidos en cuenta en cualquier diseño regulatorio que se pueda hacer sobre IA.

En segundo lugar, deben promulgarse leyes sectoriales, para las distintas áreas de influencia la IA, y que entreguen respuestas a problemáticas concretas, como el régimen de responsabilidad, la automatización del trabajo y la destrucción del empleo, o la protección de nuestros datos personales.

En este sentido, Bennet expresa que existen cuatro razones para que el cambio tecnológico pueda dar lugar a nuevas normas: (1) cuando se necesite regular nuevas conductas; (2) cuando esa nueva conducta genere incertidumbre en las reglas existentes. No queda claro si dicha conducta está ordenada, prohibida o autorizada; (3) cuando las nuevas tecnologías exceden el alcance de las reglas existentes. Las normas no fueron formuladas teniendo en mente las nuevas tecnologías; (4) cuando las reglas se basan en premisas que ya no existen, y, por lo tanto, no están justificadas, no son importantes o no son rentables ${ }^{96}$.

La IA ha dado lugar a situaciones contempladas en los cuatro supuestos antes referidos. El uso redes sociales, la utilización de bots con fines políticos, la contratación electrónica, la automatización del empleo, los coches autónomos, la telemedicina, los bancos comerciales virtuales, las bases de datos avanzadas, el blockchain, las aplicaciones para teléfonos celulares, son algunas actividades habituales en que recurrimos a sistemas inteligentes, y que exceden las posibilidades de respuesta de los marcos jurídicos vigentes.

La regulación de la IA es inminente, y cuando ocurra — expresan Cath et al. para referirse a la legislación estadounidense-, "debe apuntar a adaptarse a la IA en esquemas regulatorios existentes, por ejemplo, la automoción y la aviación”. De esta forma, el giro no será tan brusco ${ }^{97}$. Disentimos de esta propuesta, pues los esquemas regulatorios existentes, incluso aquellos modernos como los de automoción y aviación, están desarrollados sobre una lógica de avances tecnológicos distintos a la tecnología IA que, como hemos reiterado, se dirige rápidamente a la autonomía y la consciencia de las máquinas. Por tanto, esta metodología para la 
regulación de la IA, generaría marcos normativos de escasa proyección en el tiempo y obligaría a sucesivas reformas.

En definitiva, el estado del arte en IA, y los conflictos que se han suscitado con su uso - que aumenta exponencialmente-, ha obligado al derecho a dar respuestas a partir de las normas existentes y con un importante esfuerzo jurisprudencial. No obstante, el ordenamiento vigente sigue respondiendo a estructuras y lógicas extemporáneas. Se hace necesaria una profunda reflexión en torno al derecho de hoy, y a partir de ahí diseñar un sistema jurídico normativo, flexible y que se adapte a nuevas relaciones jurídicas tributarias de la sociedad tecnológica.

\section{Promover una IA centrada en la persona humana}

Un segundo desafío que se presenta al derecho es la promoción de una IA centrada en la persona humana. En este sentido, la Comisión Europea señala que:

Los sistemas de IA deben ayudar a las personas a elegir mejor y con más conocimiento de causa en función de sus objetivos. Deben actuar como facilitadores de una sociedad floreciente y equitativa, apoyando la intervención humana y los derechos fundamentales y no disminuir, limitar o desorientar la autonomía humana. El bienestar global del usuario debe ser primordial en la funcionalidad del sistema. ${ }^{98}$

Esto significa que la regulación de la IA debe ser respetuosa con los derechos fundamentales. Especialmente, el uso de IA predictiva está siendo cuestionada por vulneraciones a los principios de igualdad y de no discriminación. Algunas bases de datos y algoritmos de sistemas inteligentes utilizados para actividades de seguridad estarían provocando casos inadmisibles de "discriminación algorítmica" 99 . Por ejemplo, diversas noticias alertaron que el programa de evaluación de riesgos COMPAS, utilizado por los jueces de EE. \#UU. para predecir la tasa de reincidencia, cuando decidían sobre libertades condicionales o permisos penitenciarios, atribuía tasas de reincidencia mucho mayores (77\%) a las personas negras que a las blancas, siendo sus resultados inexactos en el $80 \%$ de los $\operatorname{casos}^{100}$.

Podemos ver que la IA, especialmente cuando es usada para reconocimiento facial o predicción de comportamientos (tasas de reincidencia), parece arrastrar las situaciones de discriminación histórica de determinados colectivos. De esta forma, es necesario que las tecnologías con IA respeten la dignidad humana y los derechos fundamentales como requisito esencial para su desarrollo. En este sentido, el Parlamento Europeo advierte que

las actividades de investigación en materia de robótica deben respetar los derechos fundamentales; y por su parte, las actividades de concepción, ejecución, difusión y explotación, por su parte, han de estar al servicio del bienestar y la autodeterminación de las personas y de la sociedad en general. La dignidad y la autonomía humanas — tanto físicas como psicológicas - siempre tienen que respetarse. ${ }^{101}$

En esta línea, dos de los casos prácticos revisados en el apartado anterior - la destrucción de empleo por la automatización de los procesos y el uso de bots para influir en los procesos eleccionarios-, en el fondo son problemas de derechos fundamentales. Lo mismo sucede con la gestión de datos y los problemas de privacidad que ello ha generado. Detrás de todas las controversias que han suscitado las mayores dudas sobre la fortaleza del derecho vigente frente a la IA hay un conflicto de derechos fundamentales.

Estamos, por tanto, ante la máxima preocupación que genera el uso intensivo de la IA, desde una perspectiva jurídica. Y la solución debe provenir del fortalecimiento de los derechos fundamentales frente a la IA, y su adaptación teórica y práctica a las relaciones jurídicas que ha generado el desarrollo de esta tecnología. Se hace necesaria una reconstrucción de la teoría de los derechos fundamentales, a la luz de las tecnologías de IA.

Pero, de acuerdo con la muy interesante propuesta de Krausová, se trata de una cuestión de ida y vuelta cuando hablamos de derechos fundamentales e IA. La cada vez mayor capacidad de la IA para comunicarse 
con los humanos en un lenguaje natural, y ante la posibilidad de que esta tecnología comience a producir contenidos originales por sí misma, cabría preguntarse si epodría dar lugar a que sus expresiones estén protegidas por la doctrina de la libertad de expresión? ${ }^{102}$

Asimismo, el incentivo de una IA centrada en las personas obliga a generar normas relativas a la responsabilidad, la transparencia y la rendición de cuentas, que permita garantizar el uso responsable de la IA. Esto significa que se "debe garantizarse la trazabilidad de los sistemas de IA". Es decir, registrar y documentar las decisiones tomadas por los sistemas y los procesos que permitieron esa decisión. Se busca en definitiva que, las decisiones de un sistema de IA, cuenten con mecanismos de explicabilidad suficientes. Asimismo, se debe "comunicar adecuadamente las capacidades y limitaciones del sistema de IA a las distintas partes interesadas". Finalmente, los sistemas de IA deben ser "identificados como tales, garantizando que los usuarios sepan que están interactuando con un sistema de IA y qué personas son responsables del mismo" ${ }^{103}$.

Finalmente, el tema que parece más espectacular, cuando hablamos de la necesidad de promover una IA centrada en las personas. Como hemos visto, el progreso que ha habido en autonomía y determinados niveles de consciencia de las máquinas dotadas de IA, nos obliga a replantear el régimen relativo a la responsabilidad. La idea que haya robots u otros dispositivos con IA que, actuando de manera autónoma, puedan generar daños, ha llevado a la Unión Europea a plantear abiertamente la incorporación de la persona electrónica. De esta forma, se avanzaría hacia una teoría de la personalidad que abarque a las personas humanas o naturales, las personas jurídicas y personas electrónicas. En este sentido, el Parlamento Europeo, en su Resolución de 2017, solicita a la Comisión, que

la futura legislación, explore, analice y considere las implicancias de todas las posibles soluciones jurídicas, tales como: [...]f) Crear a largo plazo una personalidad jurídica específica para los robots, de forma que como mínimo los robots autónomos más complejos puedan ser considerados personas electrónicas responsables de reparar los daños que puedan causar, y posiblemente aplicar la personalidad electrónica a aquellos supuestos en los que los robots tomen decisiones autónomas inteligentes o interactúen con terceros de forma independiente. ${ }^{104}$

Como podemos suponer, de avanzarse en la idea de desarrollar un régimen de la personalidad electrónica para robots que adopten decisiones autónomas inteligentes, a fin que puedan asumir la responsabilidad de sus actos, rompe absolutamente los esquemas de las estructuras tradicionales del derecho y nos lleva a una dimensión desconocida difícil de proyectar. No obstante, el derecho debe prepararse para avanzar también por esa vía que, visto el avance logrado en IA en los últimos años, parece ser la adecuada.

\section{Regular sin entorpecer la innovación}

Por último, un desafío que guarda relación con el equilibrio normativo. Esto es, que la protección efectiva los derechos fundamentales de la persona, y las normas que promuevan un uso responsable de la IA (responsabilidad, transparencia y rendición de cuentas), no dé lugar a un marco jurídico que desincentive o entorpezca la innovación en IA.

Sobre este tema, el Comité Económico y Social Europeo ha expresado que:

la humanidad se encuentra a las puertas de una era en la que robots, bots, androides y otras formas de inteligencia artificial cada vez más sofisticadas parecen dispuestas a desencadenar una nueva revolución industrial — que probablemente afecte a todos los estratos de la sociedad—, resulta de vital importancia que el legislador pondere las consecuencias jurídicas y éticas, sin obstaculizar con ello la innovación. ${ }^{105}$

En el mismo sentido, el Parlamento Europeo señala:

que es necesario disponer de una serie de normas en materia de responsabilidad, transparencia y rendicio\#n de cuentas que reflejen los valores humanistas intrínsecamente europeos y universales que caracterizan la contribución de Europa a 
la sociedad; que esas normas no deben afectar al proceso de investigación, innovación y desarrollo en el ámbito de la robo\#tica. ${ }^{106}$

Hacia esta idea apunta la noción de entorno amigable para la IA, que se enunciaba antes. La transformación digital está en marcha, y por tanto, se hace necesario un marco normativo que genere incentivos para que todas las industrias estén en condiciones de adoptar la IA, aumentando la competitividad de los países.

Estimamos que estos tres son los principales desafíos sobre los que se deben articular los regímenes jurídicos para la IA, que deberán comenzar a elaborar los países para intentar adecuar el derecho a esta tecnología, que está comenzando a producir importantes transformaciones sociales, marcando una distancia contraproducente con nuestros sistemas jurídicos.

\section{Conclusiones}

La IA está transformando nuestro mundo. En sus diversas manifestaciones comienza a estar presente en nuestras vidas, sin que siquiera nos percatemos. Concebida como una herramienta para facilitar la vida a las personas, los avances deslumbrantes que ha tenido esta ciencia, desde su creación, en la década de 1950, han comenzado a dar lugar también a algunos problemas, de relevancia jurídicas, derivados de los riesgos que su uso está implicando.

La progresión en autonomía y determinados niveles de consciencia de los sistemas de IA ha llevado a situaciones en que estos toman decisiones inteligentes y, por tanto, son capaces de producir daño a las personas o a sus bienes.

Desde esta perspectiva, los problemas que se han generado con el uso de IA han dejado de ser conflictos éticos para situarse la esfera del derecho. Diversos problemas de carácter jurídico se han comenzado a suscitar y las respuestas se han buscado en los marcos normativas existentes.

No obstante, las características de las relaciones jurídicas que han nacido en torno a esta tecnología han dado lugar a problemas complejos que exceden, con creces, las posibilidades del derecho vigente de buena parte de los ordenamientos jurídicos más avanzados.

En este sentido, se propone en este estudio la necesidad de avanzar en un marco normativo que pueda dar respuesta a las diversas problemáticas que plantea la IA. Para lograr este objetivo, se identifican tres grandes desafíos para el derecho.

En primer lugar, avanzar en un desarrollo normativo en dos dimensiones. Por una parte, desarrollar una teoría jurídica propia para la IA que permita la adaptación del derecho a las particularidades de la IA. Esto implica elaborar, por una parte, un marco normativo que contenga normas generales, principios éticos y jurídicos, estándares y criterios que orienten el diseño regulatorio para esta tecnología. Por otra parte, se requiere avanzar en normas sectoriales para ir dando respuesta a las diversas temáticas que van surgiendo, especialmente en derecho civil, penal, ambiental, laboral, etc.

Un segundo desafío es la promoción de una IA centrada en la persona humana. Todas las actividades relativas a la IA, incluida la legislativa, deben poner el foco en que la IA está al servicio de la persona humana. Ello implica desarrollar una IA respetuosa de los derechos fundamentales, y con normas claras sobre responsabilidad, transparencia y rendición de cuentas, a fin de garantizar el uso responsable de la IA. Asimismo, significa adecuar las normas de responsabilidad al estadio actual de la ciencia sobre IA, que incluya integrar, eventualmente, a la persona electrónica, proyectando una teoría de la personalidad con personas humanas o naturales, personas jurídicas y personas electrónicas.

Finalmente, el tercer desafío es que la regulación que se genere no desincentive o entorpezca la innovación en IA. Deberán los legisladores buscar un equilibrio entre la protección de los derechos fundamentales y el desarrollo de reglas efectivas de responsabilidad, transparencia y rendición de cuentas con los incentivos suficientes para que se siga progresando en IA, para que esta tecnología se pueda adaptar en todas las 
actividades industriales. Desde esta perspectiva, debe primar una regulación amistosa con la IA, que permita la transformación digital de las empresas, haciéndolas competitivas en los mercados internacionales.

\section{Bibliografía}

Antonio-Enrique Pérez Luño, VitorioFrosini y los nuevos derechos de la sociedad tecnológica, Informática e diritto 18, 1, 101-112 (1992).

Arantzazu Vicandi, El contrato de seguro de automóvil frente a los coches autónomos: luces y sombras de los smart cars, Revista de Derecho, Empresa y Sociedad 14, 101-109 (2019).

Aubrey Milunsky \& George Annas, eds., Genetics and the Law (Springer, 2012).

Bart Verheij, Artificial Intelligence as Law, Artificial Intelligence and Law 28, 181-206 (2020).

Camilo Narváez, La inteligencia artificial entre la culpa, la responsabilidad objetiva y la responsabilidad absoluta en los sistemas jurídicos del Derecho continental y anglosajón, en Jhoel Chipana, coord., Derecho y nuevas tecnologías. El impacto de una nueva Era 211-227 (Thêmis, 2019).

Comisión Europea, Generar confianza en la inteligencia artificial centrada en el ser humano, COM (2019) 168 final, 8 de abril de 2019.

Comisión Europea, Inteligencia artificial para Europa, COM (2018) 237 final, de 25 de abril de 2018. DOUE SWD (2018) 137 Final.

Comisión Europea, Libro blanco sobre la inteligencia artificial. Un enfoque europeo orientado a la excelencia y la confianza, COM (2020) 65 final, 19 de febrero de 2020, 1.

Comité Económico y Social Europeo, Dictamen sobre "Inteligencia artificial: anticipar su impacto en el trabajo para garantizar una transición justa” (2018/C 440/01).

Corinne Cath et al., Artificial Intelligence and the "Good Society.: the US, EU, and UK approach, Science and Engineering Ethics 24, 505-528 (2018).

Corinne Cath, Governing artificial intelligence: ethical, legal and technical opportunities and challenges, Philosophical Transactions of the Royal Society A: Mathematical, Physical and Engineering Sciences 237, 2133, 1-8 (2018).

D. Vosoughi Roy \& S. Aral, The spread of true and false news online, Science 359, 6380, 1146-1151 (2018).

David Baumer, Julia Earp \& J. C. Poindexter, Internet privacy law: a comparison between the United States and the European Union, Computers \& Security 23, 5, 400-412 (2004).

David Wilkinson, Environment and Law (Routledge, 2002).

Eduardo Carrasco, Relación cronológica entre la ley y la realidad social. Mención particular sobre la "elasticidad de la ley", Ius et Praxis 23, 1, 555-578 (2017).

Eduardo Novoa, El derecho como obstáculo al cambio social (5.. ed., Siglo XXI Eds., 1981).

Emilio García et al., Nuevas perspectivas cientificas y filosóficas sobre el ser humano (Universidad Pontificia de Comillas, 2007).

European Parliament, Draft Report with recommendations to the Commission on a framework of ethical aspects of artificial intelligence, robotics and related technologies. Proposal for a Regulation of the European Parliament on ethical principles for the development, deployment and use of artificial intelligence robotics and related technologies, 2020/2012 (INL), 21 de abril de 2020.

Fernando Galindo, ¿Inteligencia artificial y derecho? Sí, pero ¿cómo?, Revista Democracia Digital e Gobernó Electrónico $1,18,36-57$ (2019).

Francisca Ramón Fernández, Robótica, inteligencia artificial y seguridad: ¿cómo encajar la responsabilidad civil? Diario La Ley 9365, 1-13 (2019).

Francisco Escolano, Miguel Cazorla, María Alfonso, Otto Colomina \& Miguel Lozano, Modelos, técnicas y áreas de aplicación (Thomson, 2003). 
G. Cole, Tort liability for artificial intelligence and expertsystems, Computer/Law Journal 10, 2, 127-232 (2000). http:// heinonline.org/HOL/Page?handle=hein.journals/jmjcila10\&start_page=127\&collection=journals\&id=131.

George Stigler, The Theory of Economic Regulation, Bell Journal of Economics and Management Science 2, 1, 3-21 (1971).

Germà Bel, Joan Calzada \& Alejandro Estruch, Economía y regulación de los servicios de red, en Santiago Muñoz Machado et al., Derecho de la regulación económica 707-758 (vol. I, Iustel, 2009).

Gustavo Zagrebelsky, El derecho dúctil. Ley, derechos, justicia (trad. de M. Gascón) (5.. ed., Trotta, 2003).

Herbert Simon, Studying Human Intelligence by Creating Artificial Intelligence. When considered as a physical symbol system, the human brain can be fruitfully studied by computer simulation of its processes, American Scientist 69, 3, 300-309 (1981).

Idoia Elizalde, Vehiculos autónomos. Desplazamiento de las reglas de responsabilidad civil del propietario al fabricante. Criticas a la propuesta. El riesgo de la circulación seguirá existiendo, en María José Santos, Pedro Del Olmo \& Jesús Mercader, Dir., Nuevos retos del Derecho de Daños en Iberoamérica. I Congreso Iberoamericano de Responsabilidad Civil, 841-858 (Tirant lo Blanch, 2020).

J. Feldmann, Connectionist models and their application: Introduction, Cognitive Science 6, 205-254 (1985).

Javier Cremades, Miguel Fernández-Ordóñez \& Rafael Illescas, coords., Régimen Jurídico de Internet (La Ley, 2002).

John McCarthy, Making Robots Conscious of their Mental States 1-39 (2002), http://www-formal.stanford.edu/jmc/ consciousness.ps.

Jorge Torres, Breves consideraciones acerca del aterrizaje de la inteligencia artificial en el derecho y su influencia en la realización de los derechos fundamentales, Pensamiento Americano 10, 19, 221 210-227 (2017).

José Beltrán, Aproximación al régimen jurídico de las redes sociales, Cuaderno Electrónico de Estudios Jurídicos, 2, 61-90 (2014).

José Luis Serrano, Ecologia y derecho. Principios de derecho ambiental y ecología jurídica (Trotta, 1992).

Josep Corbí \& Josep Prades, El conexionismo y su impacto en la filosofía de la mente, en F. Brocano, ed., La mente humana 151-174 (Trotta, 1995).

L. M. Gonzalo, Inteligencia humana e inteligencia artificial, Revista de Medicina de la Universidad de Navarra XXXIX, 4, 273-274 (1985).

Lawrence Friedman \& J. Landinski, El derecho como instrumento de cambio social incremental, Revista de Derecho PUCP 27, 22-34 (1969).

Lorenzo Cotino, Ética en el diseño para el desarrollo de una inteligencia artificial, robótica y big data confiables y su utilidad desde el derecho, Revista Catalana de dret públic 58, 29-48 (2019).

Lorenzo Cotino, Riesgos e impactos del big data, la inteligencia artificial y la robótica. Enfoque modelos y principios de la respuesta del derecho, Revista General del Derecho Administrativo 50, 1-37 (2019).

Lotte Asveld \& Sabine Roeser, ed., The Ethics of Technological Risk (Routledge, 2009).

Luis Amador, Inteligencia artificial y sistemas expertos (Universidad de Córdoba, 1996).

Luis Santana \& Gonzalo Huerta, ¿Son bots? Automatización en redes sociales durante las eleccionespresidenciales de Chile 2017, cuadernos.info 44, 61-77 (2019).

Lyria Bennet, Agents of Change. How the Law 'Copes? With Technological Change, Griffith Law Review 20, 763-794 (2014).

Lyria Bennet, Why Have a Theory of Law and Technological Change?, Minnesota Journal of Law Science \& Technology 8, 2, 589-606 (2007).

M. Carmen Núñez, Los nuevos retos de la Unión Europea en la regulación de la responsabilidad por los daños causados por la inteligencia artificial, Revista Española de Derecho Europeo 66, 9-53 (2018).

Manuel Atienza, Filosofía del derecho y transformación social (Trotta, 2017).

María del Pilar Álvarez, Desafíos legales ante la circulación de los coches autónomos. Implicancias éticas, responsabilidad por accidente y ciberseguridad, Aranzadi civil-mercantil, Revista doctrinal 2, 129-138 (2017). 
María José Santos, Regulación legal de la robótica y la inteligencia artificial: retos de futuro, Revista Jurídica de la Universidad de León 4, 25-50 (2017).

Marina Pietrangelo, La società dell'informazione tra realtà e norma (Dott. A. Guifré Editore, 2007).

Natalie Persily, The 2016 U.S. Election: ¿Can Democracy Survive the Internet?, Journal of Democracy 28, 2, 63-76 (2017).

Oriol Mir, Globalización, Estado y derecho. Las transformaciones recientes del derecho administrativo (Civitas, 2004).

Parlamento Europeo, Resolución de 17 de febrero de 2017, con recomendaciones destinadas a la Comisión sobre normas de Derecho Civil sobre robótica. P8_TA (20017) 0051.

Paul Thagard, La mente. Introducción a las ciencias cognitivas (trad. de Silvia Jawerbaum \& Julieta Barba, Katz Eds., 2008).

Paulius Cerka, Jurgita Grigienè \& Gintarè Sirbikytè, Liability for damages caused by artificial intelligence, Computer Law \& Security Review 31,3, 376-389 (2015).

Phillip Howard, Samuel Woolley \& Ryan Calo, Algorithms, bots, and political communication in the US 2016 election: The challenge of automated political communication for election law and administration, Journal of Information Technology \& Politics 15, 2, 81 (2016).

Pompeu Casanovas, Derecho tecnologia, inteligencia artificial y web semántica. Un mundo para todos y para cada uno, en J. L. Fabra, ed., Enciclopedia de filosofía del derecho y teoría del derecho 825 (UNAM, serie Doctrina Jurídica, 172, vol. I, 2015).

Pompeu Casanovas, Inteligencia artificial y derecho: a vuelapluma, Teoría \& Derecho. Revista de Pensamiento Jurídico 7, 203-221 (2010).

Raúl Benítez, Gerard Escudero, Samir Kanaan \& David Masip, Inteligencia artificial avanzada (Ed. UOC, 2013).

Roger Brownsword, Rights, Regulation and the Technological Revolution (Oxford University Press, 2008).

Ronald Chrisley, Artificial Intelligence. Critical Concepts (vol. I, Routledge, 2000).

Ronald Chrisley, The Development of the Concept of Artificial Intelligence. Historical Overviews and Milestones, en Ronald Chrisley, Artificial Intelligence. Critical Concepts 7-24 (vol. I, Routledge, 2000).

S. Andersen, John McCarthy: father of AI, IEEE Intelligent Systems 17, 5, 84-85 (2002).

Salvador Contreras, La protección del honor, la intimidada y la propia imagen en internet (Cizur Menor, Thomson Reuters-Aranzadi, 2012).

Sonja Starr, Evidence-Based Sentencing and the Scientific rationalization of Discrimination, Stanford Law Review 66, 803-872 (2014).

Ulrich Beck, La sociedad del riesgo: hacia una nueva modernidad (Paidós, 2006).

Valentina Manzur, Responsabilidad por daños causados por robots: ¿responsabilidad objetiva o gestión de riesgos?, en, María José Santos, Pedro Del Olmo \& Jesús Mercader, Dir., Nuevos retos del Derecho de Daños en Iberoamérica. I Congreso Iberoamericano de Responsabilidad Civil 879-898 (Tirant lo Blanch, 2020).

Vittorio Frosini, Cibernética, derecho, internet y sociedad (Olejnik, 2019).

Vittorio Frosini, L'uomo artificiale. Etica e dirijo nell'era planetaria 122 y ss. (Spirali, 1986).

W. Bechtel \& A. Abrahamsen, Connectionism as the mind (Blackwell, 1991).

W. Price, S. Gerke \& I. Cohen, Potential Liability for physicians using artificial intelligence, JAMA 322, 18, 1765-1766 (2019).

World Commission on Environmen Development, Our Common Future (Oxford University Press, 1987).

Yochai Benkler, The wealth of networks: How social production transforms markets and freedom (Yale University Press, 2006).

Yuriy Gorodnichenko, Tho Pham \& Oleksandr Talavera, Social Media, Sentiment and Public Opinions: Evidence form \#BREXIT and \#USELECTION, BER Working Paper Series, Working Paper 2463, 3 (2018). 


\section{Notas}

* Artículo de investigación científica

1 Seguiremos en este estudio la definición de cambio social dada por Friedman y Landinski: "cualquier alteración irrepetible en los modos de conducta establecidos en sociedad". Lawrence Friedman \& J. Landinski, El derecho como instrumento de cambio social incremental, Revista de Derecho PUCP, 27, 22 (1969).

2 Para profundizar el estudio de esta cuestión, véase Eduardo Carrasco, Relación cronológica entre la ley y la realidad social. Mención particular sobre la "elasticidad de la ley", Ius et Praxis 23, 1, 555-578 (2017).

3 Sobre esta temática, véase Manuel Atienza, Filosofía del derecho y transformación social (Trotta, 2017). También, Eduardo Novoa, El derecho como obstáculo al cambio social (Siglo XXI Eds., 1981).

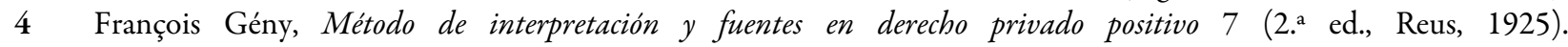

5 Zagrebelsky habla de Derecho dúctil o fluido, para proponer nuevas formas en que debe operar el derecho en este mundo globalizado. En Gustavo Zagrebelsky, El derecho dúctil. Ley, derechos, justicia (trad. M. Gascón) (5.a ed., Trotta, 2003).

6 El desarrollo científico y tecnológico ha traído consigo un conjunto de riesgos inimaginables hasta hace no muchos años. Sobre esta cuestión, véase Ulrich Beck, La sociedad del riesgo: hacia una nueva Modernidad (Paidós, 2006). De la misma forma, y relacionado también con la evolución de la ciencia y la tecnología, podemos ver que se ha ido configurando en la sociedad un nuevo valor en torno a la sostenibilidad. Sobre este tema, véase World Commission on Environment Development, Our Common Future (Oxford University Press, 1987).

7 Para revisar los avances de la jurisprudencia en estas cuestiones, véase José Beltrán, Aproximación al régimen jurídico de las redes sociales, Cuaderno Electrónico de Estudios Jurídicos 2, 61-90 (2014); Salvador Contreras, La protección del honor, la intimidada y la propia imagen en internet (Cizur Menor, Thomson Reuters-Aranzadi, 2012).

8 Véase Aubrey Milunsky \& George Annas, edit., Genetics and the Law (Springer, 2012).

9 Véase David Baumer, Julia Earp \& J. C. Poindexter, Internet privacy law: a comparison between the United States and the European Union, Computers \& Security 23,5, 400-412 (2004); Javier Cremades, Miguel Fernández-Ordóñez \& Rafael Illescas, coords., Régimen jurídico de internet (La Ley, 2002).

10 Para profundizar en estos temas, véase Vittorio FROSINI, Cibernética, derecho, internet y sociedad (Olejnik, 2019); Marina Pietrangelo, La società dell'informazione tra realtà e norma (Dott. A. Guifré Editore, 2007).

11 Lyria Bennet, Agents of Change. How the Law 'Copes? With Technological Change, Griffith Law Review 20, 763 (2014).

12 Lyria Bennet, ¿Why Have a Theory of Law and Technological Change?, Minnesota Journal of Law Science \& Technology 8, 2, 598 (2007).

13 La Conferencia de Darmouth (Darmouth Summer Research Project on Artificial Intelligence), celebrada en el Darmouth College, EE.UU., en 1956, fue la primera reunión científica en que se discutió acerca de los incipientes trabajos que se estaban realizando en el campo de lo que denominaron inteligencia artificial. Para una revisión del concepto y la evolución de la inteligencia artificial (IA), véase Ronald Chrisley, Artificial Intelligence. Critical Concepts (vol. I, Routledge, 2000), Luis Amador, Inteligencia artificial y sistemas expertos (Universidad de Córdoba, 1996).

14 Francisco Escolano, Miguel Cazorla, María Alfonso, Otto Colomina \& Miguel Lozano, Modelos, técnicas y áreas de aplicación 5 (Thomson, 2003).

15 Para revisar los fundamentos del conexionismo, véase W. Bechtel \& A. Abrahamsen, Connectionism as the mind (Blackwell, 1991). También, J. Feldmann, Connectionist models and their application: Introduction. Cognitive Science 6, 205-254 (1985).

16 Francisco Escolano et al., supranota 14.

17 Josep Corbí \& Josep Prades, El conexionismo y su impacto en la filosofía de la mente, en F. Brocano, ed., La mente humana 151 (Trotta, 1995).

18 Josep Corbí \& Josep Prades, El conexionismo y su impacto en la filosofía de la mente, en F. Brocano, ed., La mente humana 151-152 (Trotta, 1995).

19 Pompeu Casanovas, Inteligencia artificial y derecho: a vuelapluma, Teoría \& Derecho, Revista de Pensamiento Jurídico 206 (2010).

20 Distintos medios de comunicación recogían en 2013 la noticia referida a la inauguración en China del primer restaurante atendido exclusivamente pro robots. Por todas, véase la nota de prensa de National Geographic de 2013: https://www. ngenespanol.com/traveler/restaurante-futurista-atendido-por-robots-en-china/

21 Francisco Escolano et al., supra nota 14, pág. 8.

22 Sobre esta idea, véase Camilo Narváez, La inteligencia artificial entre la culpa, la responsabilidad objetiva y la responsabilidad absoluta en los sistemas jurídicos del derecho continental y anglosajón, en Jhoel Chipana, coord., Derecho y nuevas tecnologías. El impacto de una nueva Era 211-213 (Thêmis, 2019).

23 Luis Amador, supra nota 13, págs. 15-16.

24 Raúl Benítez, Gerard Escudero, Samir Kanaan \& David Masip, Inteligencia artificial avanzada 10 (Ed. UOC, 2013). 
31 Francisco Escolano et al., supra nota 14, pág. 8.

32 Comisión Europea, Inteligencia artificial para Europa, COM (2018) 237 final, 25 de abril de 2018.

33 Pompeu Casanovas, supra nota 19, pág. 205.

34 Id., pág. 205.

35 John McCarthy, Making Robots Conscious of their Mental States 4 (trad. propia) (2002), http://www-formal.stanford .edu/jmc/consciousness.ps.

36 Sobre esta idea, véase, S. Andersen, John McCarthy: father of AI, IEEE Intelligent Systems 17, 5, 84-85 (2002).

37 Comité Económico y Social Europeo. Dictamen sobre "Inteligencia artificial: anticipar su impacto en el trabajo para garantizar una transición justa" (2018/C 440/01).

38 Sobre estas ideas, véase Rosario Solá et al., Confianza, incertidumbre y percepción social de las tecnologias avanzadas, un caso de estudio, Revista Internacional de Sociología 67, 1, 161-175 (2009). También, Lotte Asveld \& Sabine Roeser, ed., The Ethics of Technological Risk (Routledge, 2009).

39 Sobre esta idea, Pérez Luño y Frosini han expuesto la idea de una transición desde los derechos naturales de mujeres y hombres hacia los derechos de mujeres y hombres artificiales para designar a los derechos relativos a los aspectos de nuestra vida en el mundo artificial en que estamos — cada vez más — inmersos. Ello ha obligado a replantearnos si el derecho y los derechos de los que ahora comenzamos a hablar, son la misma cosa de la que hasta hace poco hablábamos. Si bien ambos autores hacen referencia al uso de las tecnologías que nos trasladan a la vida virtual que tenemos, con nuestros perfiles en Whatsapp, Facebook, Instagram, Twitter, Telegram y otras redes sociales, nos sirve para ilustrar de igual manera lo que está sucediendo con la IA. Cabe preguntarnos si el derecho de hoy, inmerso en una sociedad tecnológica, es el mismo que el conocíamos hasta hace poco. Antonio-Enrique Pérez Luño, Vitorio Frosini y los nuevos derechos de la sociedad tecnológica, Informática e diritto 18, 1, 105 (1992); V. Frosini, L'uomo artificiale. Etica e dirijo nell'era planetaria 122 y ss. (Spirali, 1986). Sobre esta temática, también, véase Lorenzo Cotino, Riesgos e impactos del big data, la inteligencia artificialy la robótica. Enfoque modelos y principios de la respuesta del derecho. Revista General del Derecho Administrativo 50, 1-37 (2019).

40 La idea de disrupción tecnológica fue propuesta por Mercader, para hacer referencia a "la tecnología que altera el status quo que existe e innova radicalmente la realidad productiva”. Valentina Manzur, Responsabilidad por daños causados por robots: ¿responsabilidad objetiva o gestión de riesgos?, en María José Santos; Pedro Del Olmo y, Jesús Mercader, Dir., Nuevos retos del derecho de daños en Iberoamérica. I Congreso Iberoamericano de Responsabilidad Civil 881 (Tirant lo Blanch, 2020).

41 Lyria Bennet, supra nota 12.

42 Así, por ejemplo, en la Unión Europea se comienza a discutir sobre la posibilidad de atribuir alguna categoría de sujetos de derecho a los robots inteligentes, ante los avances registrados en los grados de autonomía y rasgos cognitivos de estos, así como su capacidad de aprender y tomar decisiones independientes. De concretarse esta idea, estaríamos ante una verdadera revolución en la ciencia del derecho. En relación con este tema, véase, M. Carmen Núñez, Los nuevos retos de la Unión Europea en la regulación de la responsabilidad por los daños causados por la inteligencia artificial, Revista Española de Derecho Europeo 66, 9-53 (2018).

43 De acuerdo con Bennet, el problema de desajuste entre el cambio tecnológico y la norma ha sido objeto de análisis por distintos autores, quienes se han referido el con distintos nombres. Entre ellos, Brownsword lo ha calificado como "el desafío de la conexión regulatoria”. Roger Brownsword, Rights, Regulation and the Technological Revolution (Oxford University Press, 2008).

44 Comisión Europea, supra nota 32.

45 Id.

46 Comisión Europea, Libro blanco sobre la inteligencia artificial. Un enfoque europeo orientado a la excelencia y la confianza, COM (2020) 65 final, de 19 de febrero de 2020, 1.

47 Corinne Cath, Governing artificial intelligence: ethical, legal and technical opportunities and challenges, Philosophical Transactions of the Royal Society A: Mathematical, Physical and Engineering Sciences 237, 2133, 2 (2018). Comisión Europea, supra nota 46; Comisión Europea, supra nota 32, pág. 17. 
49 Corinne Cath, supra nota 47.

50 Bart Verheij, Artificial Intelligence as Law. Artificial Intelligence and Law 28, 184 (2020).

51 Sobre esta idea, véase Germà Bel, Joan Calzada y Alejandro Estruch, Economía y regulación de los servicios de red, en, Santiago Muñoz Machado et al., Derecho de la regulación económica 707-758 (vol. I, Iustel, 2009); Oriol Mir, Globalización, Estado y derecho. Las transformaciones recientes del derecho administrativo (Civitas, 2004); George Stigler, The Theory of Economic Regulation, Bell Journal of Economics and Management Science 2, 1, 3-21 (1971).

52 Sobre las diversas iniciativas surgidas para acordar un marco ético y jurídico base para diseña la regulación de la IA, Corinne Cath et al., Artificial Intelligence and the "Good Society": the US, EU, and UK approach, Science and Engineering Ethics 24, 505-528 (2018).

53 La noticia referida puede verse en blog de la web de Ágora, escrito por Helena Ancos, ¿Se puede despedir a un trabajador para sustituirlo por un robot?, https://www.agorarsc.org/se-puede-despedir-a-un-trabajador-para-sustituirlo-por-un-r obot/

54 Puede revisarse la sentencia del 23 de septiembre de 2019, del Juzgado de lo Social No 10 de Las Palmas de Gran Canaria, en el siguiente enlace: https://documentacion.eu/documentos/sentencia-del-juzgado-de-lo-social-no-10-de-las-palmas -de-gran-canaria-de-23-de-septiembre-de-2019/.

55 Expresa el Tribunal en su sentencia que, debe distinguirse el uso de robots, como señalaba la empresa, del uso de bots. Para la robotización de las funciones administrativas, así como de los procesos industriales, se requiere de "la forma del soporte físico del robot" (en los que se inserta IA), que realicen dichas funciones o procesos. En cambio, cuando la automatización se realiza a través de un software instalaba en cualquier servidor generalista, cabe hablar de bot (fundamento jurídico quinto).

56 Parlamento Europeo, Resolución de 17 de febrero de 2017, con recomendaciones destinadas a la Comisión sobre normas de derecho civil sobre robótica. P8_TA (20017) 0051, párr. 43.

57 Comité Económico y Social Europeo, Dictamen sobre "Inteligencia artificial: anticipar su impacto en el trabajo para garantizar una transición justa” (2018/C 440/01), apdo. 2.5.

58 Entendemos por bots a aquellos programas informáticos autónomos, creados para ejecutar tareas simples y repetitivas, a través de internet, con cierta inteligencia. Luis Santana \& Gonzalo Huerta, ¿Son bots? Automatización en redes sociales durante las elecciones presidenciales de Chile 2017, cuadernos.info 44, 62 (2019). También, Diego Rodríguez, ¿Qué es un bot y para qué sirve?, Blog de Raiola Networks. https://raiolanetworks.es/blog/que-es-un-bot/.

59 Véase la nota periodística publicada en el portal electrónico de Europapress. https://www.europapress.es/portaltic/social media/noticia-bots-twitter-influyeron-resultados-brexit-elecciones-presidenciales-eeuu-estudio-20180522150442.ht $\mathrm{ml}$.

60 Yuriy Gorodnichenko, Tho Pham \& Oleksandr Talavera, Social Media, Sentiment and Public Opinions: Evidence form \#BREXIT and \#USELECTION, BER Working Paper Series, Working Paper 2463, 2 (2018).

61 Id.

62 Luis Santana \& Gonzalo Huerta, supra nota 58, pág. 63.

63 Natalie Persily, The 2016 U.S. Election: ¿Can Democracy Survive the Internet?, Journal of Democracy, 28, 2, 63 (2017).

64 Phillip Howard, Samuel Woolley \& Ryan Calo, Algorithms, bots, andpolitical communication in the US 2016 election: The challenge of automated political communication for election law and administration, Journal of Information Technology \& Politics 15, 2, 81-82 (trad. propia) (2016).

65 Yuriy Gorodnichenko, Tho Pham \& Oleksandr Talavera, supra nota 60, pág. 20.

66 Id, págs. 19-21.

67 Luis Santana \& Gonzalo Huerta, supra nota 58, pág. 63. En el mismo sentido, Roy, D. Vosoughi \& S. Aral, The spread of true and false news online. Science, 359, 6380, 1146-1151 (2018). También, Natalie Persily, supra nota 63, págs. 64-66 (2017).

68 Por todas las notas periodísticas que informan de la crisis social en Chile, véase la publicada en Time: "18 Killed as Hundreds of Thousands of Protestors Take the Streets in Chile. Here's What to Know”. https://time.com/5710268/ chile-protests/.

69 Sobre este tema, véase la nota publicada en el periódico chileno La Tercera: "El big data del Gobierno: Los detalles del informe por el estallido social que entregó a la Fiscalía”. https://www.latercera.com/la-tercera-domingo/noticia/big-da ta-del-gobierno-los-detalles-del-informe-estallido-social-entrego-la-fiscalia/947967/.

70 Véase la siguiente nota "Gobierno de Chile entrega detalles de grupos que influenciaron la protesta violenta y el estallido social”, que recoge esta información. https://es.theepochtimes.com/gobierno-de-chile-entrega-detalles-de-grupos-que-i nfluenciaron-la-protesta-violenta-y-el-estallido-social_582688.html.

71 Nota de prensa del portal web de Radio Bio Bio, biobiochile.cl, "No hemos encontrado ningún valor': Fiscal Abbott desecha informe Big Data entregado por La Moneda”, 15 de enero de 2020. https://www.biobiochile.cl/noticias/nacional/chile/2020/01/15/no-hemos-encontrado-ningun-valor-fiscal-ab bott-deshecha-informe-big-data-entregado-por-la-moneda.shtml. 
72 Véase la nota periodística de Vozpopuli, "El Gobierno denuncia ser víctima de 'bots' que viralizan las publicaciones de Sanidad en Facebook”, 20 de abril de 2020. https://www.vozpopuli.com/espana/Gobierno-denuncia-bots-viralizan-pu blicaciones-Sanidad-Facebook-cuentas-falsas_0_1347766570.html.

73 Nota periodística de La Vanguardia, "El Gobierno investiga perfiles falsos en redes sociales que apoyan su gestión”, 21 de abril de 2020. https://www.lavanguardia.com/politica/20200421/48651813739/gobierno-investiga-cuentas-falsas -facebook-coronavirus.html.

74 Yuriy Gorodnichenko, Tho Pham \& Oleksandr Talavera, supra nota 60, pág. 21.

75 Luis Santana \& Gonzalo Huerta, supra nota 58, pág. 62. Sobre esta misma idea, Yochai Benkler, The wealth of networks: How social production transforms markets and freedom (Yale University Press, 2006).

76 Phillip Howard, Samuel Woolley \& Ryan Calo, supranota 64, pág. 81.

77 Id., págs. 82-83.

78 Diario El País. https://elpais.com/tecnologia/2018/03/19/actualidad/1521479089_032894.html.

79 Idoia Elizalde, Vehiculos autónomos. Desplazamiento de las reglas de responsabilidad civil del propietario al fabricante. Críticas a la propuesta. El riesgo de la circulación seguirá existiendo, en María José Santos, Pedro Del Olmo \& Jesús Mercader, Dir., Nuevos retos del derecho de daños en Iberoamérica. I Congreso Iberoamericano de Responsabilidad Civil 855 (Tirant lo Blanch, 2020). Sobre esta idea, también, véase María del Pilar Álvarez, Desafíos legales ante la circulación de los coches autónomos. Implicancias éticas, responsabilidad por accidente y ciberseguridad, Aranzadi civil-mercantil, Revista doctrinal 2, 129-138 (2017).

80 De acuerdo con Vicandi, los coches autónomos son aquellos que no requieren de un conductor para circular por las calles. Se excluye, por tanto, las tecnologías que facilitan la conducción humana, por requerir la presencia activa de un chofer. Arantzazu Vicandi, El contrato de seguro de automóvil frente a los coches autónomos: luces y sombras de los smart cars, Revista de Derecho, Empresa y Sociedad 14, 101 - 109 (2019).

81 Un análisis de esta cuestión, véase Idoia Elizalde, supra nota 79, págs. 841-858.

82 Arantzazu Vicandi, supra nota 80, págs. 104-107 (2019); Idoia Elizalde, supra nota 79, págs. 855-856.

83 Para profundizar en esta temática, véase W. Price, S. Gerke \& I. Cohen, Potential Liability for physicians using artificial intelligence. JAMA, 322, 18, 1765-1766 (2019); Francisca Ramón Fernández, Robótica, inteligencia artificialy seguridad: ¿Cómo encajar la responsabilidad civil? Diario La Ley, 9365, 1-13 (2019); G. Cole, Tort liability for artificial intelligence and expert systems, Computer/Law Journal, 10, 2, 127-232 (2000). http://heinonline.org/HOL/Page?handle=hein.jo urnals/jmjcila10\&start_page $=127 \&$ collection $=$ journals\&id $=131$.

84 Parlamento Europeo, supra nota 56.

85 Id.; Francisca Ramón Fernández, supra nota 83.

86 Parlamento Europeo, supra nota 56.

87 Véase Paulius Cerka, Jurgita Grigienè \& Gintarè Sirbikytè, Liability for damages caused by artificial intelligence, Computer Law \& Security Review 31, 3, 376-389 (2015).

88 Id.

89 Sobre esta cuestión, véase Lorenzo Cotino, Ética en el diseño para el desarrollo de una inteligencia artificial, robótica y big data confiables y su utilidad desde el derecho, Revista Catalana de dret públic 58, 29-48. (2019). También, María José Santos, Regulación legal de la robótica y la inteligencia artificial: retos de futuro, Revista Jurídica de la Universidad de León 4, 25-50 (2017).

90 Tal como señalan Corinne Cath et al., en octubre de 2016 la Casa Blanca, el Parlamento Europeo y la Cámara de los Comunes del Reino Unido, comenzaron a trabajar para acordar una visión común sobre cómo preparar a la sociedad para el uso generalizado de la IA., Corinne Cath et al., supra nota 52, págs. 505-506.

91 Sobre esta idea, véase Corinne Cath et al., supra nota 52, págs. 505-528.

92 European Parliament, Draft Report with recommendations to the Commission on a framework of ethical aspects of artificial intelligence, robotics and related technologies. Proposal for a Regulation of the European Parliament on ethical principles for the development, deployment and use of artificial intelligence robotics and related technologies, 2020/2012(INL), 21 de abril de 2020.

93 Comisión Europea, Generar confianza en la inteligencia artificial centrada en el ser humano, COM (2019) 168 final, 8 de abril de 2019.

94 Id.

95 Parlamento Europeo, supra nota 56.

96 Lyria Bennet, supra nota 12, págs. 589-590.

97 Corinne Cath et al., supranota 52, pág. 509 (trad. propia).

98 Comisión Europea, supra nota 93.

99 Jorge Torres, Breves consideraciones acerca del aterrizaje de la inteligencia artificial en el derecho y su influencia en la realización de los derechos fundamentales. Pensamiento Americano 10, 19, 221 (2017). 
Darío Parra Sepúlveda, et al. Inteligencia artificial y derecho. Problemas, desafíos y opor...

100 Véase la noticia: "Racismo tecnológico: cuando es la IA quien discrimina”, de larazon.es. https://innovadores.larazon.es/ es/racismo-tecnologico-cuando-es-la-ia-quien-discrimina/. Asimismo, un análisis sobre el tema, se realiza en Sonja Starr, Evidence-Based Sentencing and the Scientific rationalization of Discrimination, Stanford Law Review 66, 803-872 (2014).

101 Parlamento Europeo, supra nota 56.

102 Alzbeta Karusová, Intersectons between law and Artificial Intelligence, International Journal of Computer 27, 1, 55-68 (2017).

103 Comisión Europea, supra nota 93.

104 Parlamento Europeo, supra nota 56.

105 Comité Económico y Social Europeo, supra nota 57, apdo. 1-2.

106 Parlamento Europeo, supra nota 56.

\section{Licencia Creative Commons CC BY 4.0}

Cómo citar este artículo: Darío Parra Sepúlveda \& Ricardo Concha Machuca, Inteligencia artificial y derecho. Problemas, desafios y oportunidades, 70 Vniversitas (2021), https://doi.org/10.11144/Javeriana.vj70.iadp 